\title{
Phase coexistence of multiple copper oxides on AgCu catalysts during ethylene epoxidation
}

Mark T. Greiner, ${ }^{1,2}$ Jing Cao, ${ }^{1}$ Travis E. Jones, ${ }^{1}$ Sebastian Beeg, ${ }^{2}$ Katarzyna Skorupska, ${ }^{1}$ Emilia A. Carbonio, ${ }^{1,3}$ Hikmet Sezen, ${ }^{3,4}$ Matteo Amati, ${ }^{4}$ Luca Gregoratti, ${ }^{4}$ Marc-George Willinger, ${ }^{1}$ Axel KnopGericke, ${ }^{1}$ Robert Schlögl ${ }^{1,2}$

*mark.greiner@cec.mpg.de

${ }^{1}$ Fritz-Haber Institute of the Max-Planck Society, Department of Inorganic Chemistry, Faradayweg 46, 14195, Berlin, Germany

${ }^{2}$ Max-Planck Institute for Chemical Energy Conversion, Department of Heterogeneous Reactions, Stiftstrasse 34-36, 45413, Mülheim an der Ruhr, Germany

${ }^{3}$ Helmholz-Zentrum Berlin für Materialien und Energie, Albert-Einstein-Strasse 15, 12489, Berlin, Germany

${ }^{4}$ Elettra-Sincrotrone Trieste, Strada Statale 14, 34149, Basovizza, Italy

\section{Abstract}

Alloy catalysts under reaction conditions are complex entities. In oxidizing atmospheres multiple phases can coexist on a catalyst's surface as a result of phase segregation and preferential oxidation. Such a scenario can result in unusual sub-stoichiometric and meta-stable phases that could play important roles in catalytic processes. For instance, $\mathrm{AgCu}$ alloys-known to exhibit enhanced epoxide selectivity in partial oxidation of ethylene-form an oxide-like surface structure under reaction conditions. Under these conditions, copper oxides are stable, while silver oxides are not. Consequently, copper segregates to the alloy's surface and forms an oxide overlayer. Little is known about the structure or function of such overlayers, and it is unknown whether they play an active role in the catalyst's enhanced selectivity. In order to develop a clearer picture of such catalysts, the current work utilizes several in-situ spectroscopic and microscopic techniques to examine the copper oxide phases that form when $\mathrm{AgCu}$ is exposed to epoxidation conditions. It is found that several forms of oxidic $\mathrm{Cu}$ coexist simultaneously on the active catalyst's surface, namely $\mathrm{CuO}, \mathrm{Cu}_{2} \mathrm{O}$ and some previously unreported form of oxidized $\mathrm{Cu}$, referred to here as $\mathrm{Cu}_{\mathrm{x}} \mathrm{O}_{\mathrm{y}}$. On-line product analysis, performed during the in-situ spectroscopic measurements, shows that increased epoxide selectivity is correlated with the presence of mixed copper oxidation states and the presence of the $\mathrm{Cu}_{\mathrm{x}} \mathrm{O}_{\mathrm{y}}$ species. These results support previous theoretical predictions that oxidic copper overlayers on silver play an active role in epoxidation. These results furthermore emphasize the need for in-situ spectromicroscopic methods to understand the complexity of alloy catalysts.

\section{Keywords}

Alloy catalyst, ethylene epoxidation, in-situ XPS, in-situ SEM, oxidation, phase segregation

\section{Introduction}

Alloys are very versatile catalysts because their electronic structures can be tuned by changing their composition. ${ }^{1}$ However, once an alloy is exposed to reaction conditions their surfaces can re-structure, preferentially oxidize and phase segregate. ${ }^{2}$ Chemical potential gradients, nucleation barriers, and 
dynamic phase transitions can give rise to multiple meta-stable phases, simultaneously coexisting on the active catalyst's surface. While these processes may cause the alloy to lose its engineered properties, they may also serendipitously give rise to emergent catalytic properties.

Silver and copper exhibit a synergy when alloyed together and used to catalyze ethylene epoxidation. ${ }^{3,4}$ The addition of a small amount $(<1 \%)$ of $\mathrm{Cu}$ to $\mathrm{Ag}$ catalysts gives rises to an increase in epoxide selectivity of about $50 \%{ }^{3,4}$ It is not known exactly how this synergy comes to be. Indeed the addition of $\mathrm{Cu}$ to $\mathrm{Ag}$ alters the electronic structure of the metal. Theoretical work has shown that on metallic $\mathrm{AgCu}$ alloys should be more selective to epoxide because the energy barrier to form epoxide from the oxametallacycle intermediate should be lower than the barrier to form the aldehyde (which leads to total combustion). ${ }^{4}$ Furthermore, theoretical ${ }^{5}$ and model UHV studies ${ }^{6-8}$ have shown that copper alone (i.e. without silver), covered with a fractional monolayer of oxygen ions, should exhibit higher epoxide selectivity than a pure silver surface.

However, under epoxidation conditions copper becomes heavily oxidized such that the metallic surface does not remain accessible to the reactants. ${ }^{9}$ Likewise, when $\mathrm{AgCu}$ alloys are exposed to epoxidation conditions, copper becomes preferentially oxidized, ${ }^{2}$ whereby copper atoms at the surface of the alloy react with oxygen to form an oxidic surface phase. Silver does not form a stable oxide at such temperatures, so that the result is a surface either decorated or coated with an oxidized form of copper. Ab-initio thermodynamics work has demonstrated that several possible copper-containing oxide-like surface structures could be stable on $\mathrm{AgCu}$ in a gas atmosphere of $\mathrm{O}_{2}$ and $\mathrm{C}_{2} \mathrm{H}_{4},{ }^{10}$ although it has not been shown experimentally that such oxides exist. Indeed, the oxidized surface phases that form on $\mathrm{AgCu}$ when placed under epoxidation conditions have not yet been thoroughly characterized experimentally. A previous in-situ XPS investigation provided spectra of $\mathrm{AgCu}$ alloys under epoxidation conditions, and showed the presence of copper in $1+$ and $2+$ oxidation states, however the exact structure of these oxides was not concluded. ${ }^{2}$

One would not expect copper oxides to be very active or selective in ethylene epoxidation. ${ }^{9}$ Previous work has shown that $\mathrm{CuO}$ exhibits very poor epoxide selectivity of ca. $1 \%$, while $\mathrm{Cu}_{2} \mathrm{O}$ can transiently exhibit a moderate epoxide selectivity of $\mathrm{ca} .28 \%$ during the phase transition to $\mathrm{CuO} .{ }^{11,12}$ Theoretical work has calculated the reaction barriers to epoxidation on hypothetical copper-oxide covered silver surfaces, and found that oxide-like surface phases could improve epoxide selectivity. ${ }^{13}$ However, as it is not certain exactly what phases actually form on the alloy's surface during epoxidation, it is not yet possible to conclude whether such phases play an active role in epoxidation. Alternately, it is possible that sub-stoichiometry in such oxides or phase transitions between oxides play an active role in the reaction network of epoxide formation.

In the present work we have performed in-situ X-ray photoelectron spectroscopy (XPS), near-edge Xray absorption fine-structure spectroscopy (NEXAFS) and in-situ environmental scanning electron microscopy (ESEM) studies on $\mathrm{AgCu}$ alloys of varying $\mathrm{Cu}$ concentrations under ethylene epoxidation conditions, and correlated the spectroscopic measurements with online product analysis. We find that epoxidation conditions result in the formation of mixed-phases of copper oxide, where both $\mathrm{Cu}^{1+} / \mathrm{Cu}^{2+}$ oxidation states are present. In-situ microscopic investigations show that the alloy's surface becomes very inhomogeneous under epoxidation conditions, with several spatially-separated phases coexisting. The spectroscopic features of such a surface can be fit using a linear sum of $\mathrm{CuO}, \mathrm{Cu}_{2} \mathrm{O}$ reference spectra, as well as a third component of an unknown oxidic form of copper $\left(\mathrm{Cu}_{\mathrm{x}} \mathrm{O}_{\mathrm{y}}\right)$. The coexistence of $\mathrm{Cu}^{1+}$ and $\mathrm{Cu}^{2+}$ and the presence of the $\mathrm{Cu}_{\mathrm{x}} \mathrm{O}_{\mathrm{y}}$ species is correlated with enhanced epoxide selectivity. Alloys that are dilute in copper tend to retain all three phases at steady state, while increasing copper concentration results predominantly in $\mathrm{Cu}^{2+}$ species. This finding suggests that the presence of silver stabilizes the lower oxidation state of copper. The spectroscopic signature of the $\mathrm{Cu}-$ 
${ }_{\mathrm{x}} \mathrm{O}_{\mathrm{y}}$ species indicates that it exhibits a unique electronic structure, as probed by valence band and NEXAFS spectroscopy. This spectroscopic evidence suggests that the unknown surface oxide may be similar to one of those predicted using ab-initio atomistic thermodynamics calculations by Piccinin et al. $^{10}$

In-situ ESEM was used to examine the morphological evolution of theses alloy catalysts with time-onstream, and revealed that the surface segregation of copper gives rise to faceting of the metallic surface and the formation of several morphologically distinct surface structures. In order to better understand the structure of the multi-phase catalyst surface, we performed spatially-resolved XPS by mapping the surface using a focused excitation source (using a zone plate). We find that some regions of the surface oxide contain exclusively $\mathrm{Cu}^{1+}$, while other regions contain a mixture of $\mathrm{Cu}^{1+}$ and $\mathrm{Cu}^{2+}$.

These results provide new insight into the nature of alloy catalysts in reactive environments, and emphasize the need for in-situ spatially-resolved spectroscopic methods to fully understand the complexity of such catalysts. Future experimental work will be needed to precisely identify the atomic composition of the surface oxides formed under reaction conditions. Such information can then be utilized in theoretical studies to determine precisely what role such oxides might play in improving catalytic performance.

\section{Experimental}

Alloy samples were prepared by impregnating a high-purity (99.999\%) Ag powder with varying amounts of $\mathrm{Cu}\left(\mathrm{NO}_{3}\right)_{2}$. The nitrate was decomposed to $\mathrm{CuO}$ by calcining at $300^{\circ} \mathrm{C}$ for three hours. This process results in $\mathrm{Ag}$ powder particles (2-5 $\mu$ m diameter), decorated with small $\mathrm{CuO}$ particles (ca. 0.1$0.2 \mu \mathrm{m}$ diameter). The $\mathrm{CuO}$ particles were then reduced to metallic $\mathrm{Cu}$ by heating in $\mathrm{H}_{2}$ at $550^{\circ} \mathrm{C}$ for one hour. The metallic $\mathrm{Cu}$ was then dissolved into the $\mathrm{Ag}$ particles by heating in $\mathrm{H}_{2}$ at $700^{\circ} \mathrm{C}$ for one hour. This process resulted in an oxide-free alloy, as confirmed by in-situ $\mathrm{O} 1 s, \mathrm{Cu} 2 p$, valence and $\mathrm{Cu} L_{3}$ photoemission spectra, and observed in-situ with ESEM. Powders were pressed into $8 \mathrm{~mm}$ diameter pellets using $50 \mathrm{mg}$ of catalyst per pellet and pressing with one ton of force.

Near-Ambient-Pressure X-ray Photoemission Spectroscopy (NAP-XPS) was carried out at the Innovative Station for In-Situ Spectroscopy (ISISS) Beamline at BESSY II, Berlin, using a differentially pumped Phoibos 150 hemispherical analyzer from Specs GmbH. The ISISS beamline is a dipole photon source, and a plane-grating monochromator, delivering $6 \times 10^{10}$ photons $/ \mathrm{s} / 0.1 \mathrm{~A}$ and an energy resolution of $>15000$ at $400 \mathrm{eV}$. NAP-XPS experiments were performed in a gas pressure of 0.3 mbar. NEXAFS spectra were measured in partial electron yield (PEY) mode or total electron yield (TEY) mode. In PEY mode, photoemitted electrons are measured using the hemispherical analyzer, whereby only electrons of a specific kinetic energy are detected. For $\mathrm{Cu} L_{3}$ spectra, the chosen kinetic energy was $914 \mathrm{eV}$ (i.e. electrons from the $\mathrm{Cu} L M M$ Auger process). For TEY mode, X-ray absorption was detected by measuring the emitted secondary electrons. This was accomplished by measuring the current at the nozzle to the analyzer. A voltage of $50 \mathrm{~V}$ was applied to the entrance nozzle of the analyzer to suppress the photoemission signal from the gas phase. By doing so, the gas phase signal becomes shifted to higher binding energy and broadened such that it is no longer detectable. Ethylene epoxidation conditions utilized a 1:1 mixture of $\mathrm{O}_{2}: \mathrm{C}_{2} \mathrm{H}_{4}$ with a total flow rate of $6 \mathrm{ml} / \mathrm{min}$. Sample heating was accomplished by illuminating the backside of the sample pellets with an infrared laser. Reaction products were analyzed using online gas chromatography (Varian Micro-GC 4900), quadrupole mass spectrometry, and proton-transfer reaction mass spectrometry (PTRMS).

ESEM experiments were performed in a FEI Quanta 200 FEG, using a differentially pumped lens column and a gaseous secondary electron detector. Gases were continually flowed into the chamber 
via mass flow controllers to a pressure of 0.3 mbar. Sample heating was accomplished through an infrared laser fed into the chamber via a fiber optics feed-through.

XPS imaging was performed at the ESCAmicroscopy Beamline at Elettra Synchrotron, Trieste, Italy. The photon energy used for imaging and spectra acquisition was $1082 \mathrm{eV}$. X-rays were focused onto the sample using Fresnel zone plates, which provided an excitation source focused to a $150 \mathrm{~nm}$ diameter spot size. Imaging was performed by rastering the sample using piezoelectric actuators, while the photoemission signal was measured using a hemispherical analyzer. The sample was a polished $\mathrm{AgCu}$ foil of 0.3 at. \% copper that was sputter annealed and oxidized in an atmosphere of 0.3 mbar 1:1 $\mathrm{O}_{2}: \mathrm{C}_{2} \mathrm{H}_{4}$ at $300^{\circ} \mathrm{C}$.

\section{Results}

\subsection{Verification of model conditions}

Silver-copper alloys are known to exhibit enhanced epoxide selectivity when reactions are carried out at atmospheric pressure. $^{3}$ However, in the present work we use in-situ electron spectroscopy/microscopy methods that restrict operating pressures to ca. 0.3-1 mbar. In order to draw conclusions from such model conditions it is necessary to validate that the reactivity trends previously observed at atmospheric pressures ${ }^{3,12}$ are reproduced under the model conditions. To this end, we have exposed reference samples of elemental $\mathrm{Ag}$, elemental $\mathrm{Cu}$ and an $\mathrm{AgCu}$ alloy (of $1 \% \mathrm{Cu}$ ) to ethylene epoxidation conditions at reduced pressure $\left(0.3 \mathrm{mbar}, 1: 1 \mathrm{O}_{2}: \mathrm{C}_{2} \mathrm{H}_{4}, 250^{\circ} \mathrm{C}\right)$ and have analyzed the product streams, as well as the photoemission spectra (not shown). These results are shown in Figure 1.

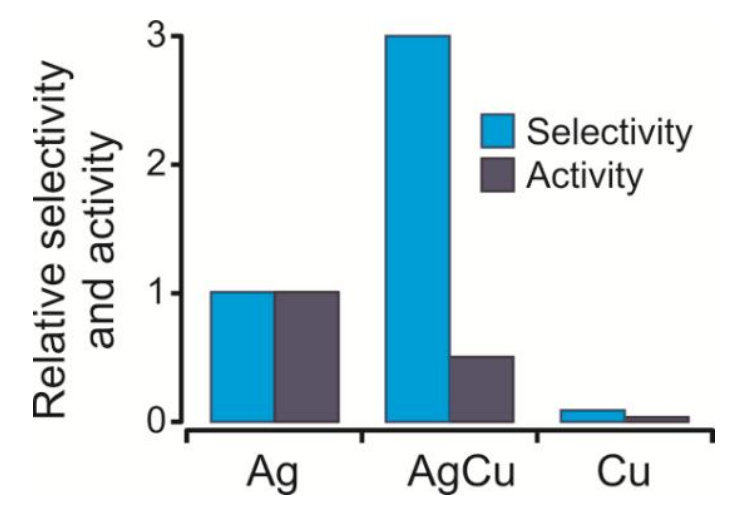

Figure 1 - Plot of relative epoxide selectivity and activity (relative to Ag) for three different catalysts measured in near-ambient-pressure conditions $\left(0.3 \mathrm{mbar}, 250^{\circ} \mathrm{C}, \mathrm{O}_{2}+\mathrm{C}_{2} \mathrm{H}_{4}\right)$. The epoxide selectivity of $\mathrm{Ag}, \mathrm{AgCu}(1 \% \mathrm{Cu})$ and $\mathrm{Cu}$ under these conditions was $6 \%, 18 \%$ and $0.5 \%$, respectively.

Figure 1 shows that the selectivity trends under the model conditions are as expected from previous atmospheric pressure studies; ${ }^{3,12}$ specifically, $\mathrm{AgCu}$ exhibits higher ethylene epoxide (EO) selectivity than elemental $\mathrm{Ag}$, and $\mathrm{Cu}$ exhibits very low epoxide selectivity and activity, with the vast majority of reaction product being $\mathrm{CO}_{2}$. Note that the scale for epoxide selectivity and activity of Figure 1 are relative to the $\mathrm{Ag}$ reference sample. The actual values are much less than ones generally achieved using an optimized plug-flow reactor. ${ }^{14-16}$ The selectivities of $\mathrm{Ag}, \mathrm{AgCu}$ and $\mathrm{Cu}$ seen here were $6 \%$, $18 \%$ and $0.5 \%$, respectively. The raw data and detailed description of the experimental set-up used for Figure 1 are available in the Supporting Information (Figure S14-S15).

One difference between the catalytic performance measured under near-ambient-pressure conditions and that measured under atmospheric pressure is that the selectivity of $\mathrm{AgCu}$ under near-ambient pressure conditions was approximately three times greater than that of elemental Ag. Previous reports 
of epoxide selectivity of $\mathrm{AgCu}$ alloys, measured at atmospheric pressure, found $\mathrm{AgCu}$ to exhibit high as 1.5 times higher EO selectivity than pure $\mathrm{Ag} .{ }^{4}$ The difference between the relative selectivities observed here and those observed previously could be a pressure effect, but may also be a result of the presence of a support in the atmospheric pressure experiments or due to the completely different flow characteristics of a plug-flow reactor compared to the NAP-XPS chamber. Regardless, of this difference, the general trends are reasonably well reproduced under near-ambient-pressure conditions.

\subsection{Chemical changes to the alloy in reaction conditions: In-situ Photoemission}

After confirming the suitability of the model conditions, we examined various $\mathrm{AgCu}$ alloys differing in $\mathrm{Cu}$ concentration, using in-situ NEXAFS and online GC product analysis. Figure $2 \mathrm{a}$ and $\mathrm{b}$ show a time-series of $\mathrm{Cu} L_{3}$ spectra from two different $\mathrm{AgCu}$ alloys under epoxidation conditions (i.e. 0.3 mbar of a 1:1 mixture of $\mathrm{O}_{2}+\mathrm{C}_{2} \mathrm{H}_{4}$ at $250{ }^{\circ} \mathrm{C}$ ). The corresponding activity and selectivity data during these measurements is also shown. One alloy had a low $\mathrm{Cu}$ content $(0.5$ at. \%), while the other had a high $\mathrm{Cu}$ content $(2.0$ at\%). Note that the maximum solubility of $\mathrm{Cu}$ in $\mathrm{Ag}$ at the reaction temperature of $250^{\circ} \mathrm{C}$ is between one and two atomic percent. ${ }^{17}$

From the NEXAFS spectra shown in Figure 2 one sees that, immediately upon exposure to reaction conditions, the $\mathrm{Cu}$ signal increases in intensity. The reason for this signal increase is that, in the presence of $\mathrm{O}_{2}$ at elevated temperatures, copper diffusing to the surface reacts with $\mathrm{O}_{2}$ to form an oxide. After forming an oxide, copper is no longer soluble in silver and remains trapped at the surface. The spectrum shape and $\mathrm{Cu} L_{3}$ absorption edge position in Figure 2a suggest that copper is initially in the $1+$ oxidation state, and with increasing time-on-stream $\mathrm{Cu}^{2+}$ begins to form. At steady state the surface of the dilute $\mathrm{AgCu}$ catalyst contains a mixture of $\mathrm{Cu}^{1+}$ and $\mathrm{Cu}^{2+}$, with $\mathrm{Cu}^{1+}$ being the majority component. In contrast, for the concentrated $\mathrm{AgCu}$ catalyst, the $\mathrm{Cu}^{2+}$ signal continues to grow with time and eventually becomes the majority component.

Note that XPS spectra were also measured during these experiments (see Supporting Information Figure S3); however, the most telling information came from the $\mathrm{Cu} L_{3}$ edge due to its very high sensitivity to $\mathrm{Cu}$ oxidation state. The $\mathrm{Cu} 2 p$ yielded essentially the same information as the $\mathrm{Cu} L_{3}$ edge, but with a lower signal intensity and poorer resolution. The $\mathrm{O} 1 s$ region consisted of multiple broad species within a small energy window, making unambiguous identification of the oxygen species impossible. The Ag3d spectra were indistinguishable from $\mathrm{Ag} 3 d$ spectra on pure $\mathrm{Ag}$ in epoxidation conditions (i.e. no influence from the presence of $\mathrm{Cu}$ could be detected). The Ag spectra consisted of a metallic Ag peak, with a low-binding energy shoulder attributed to $\mathrm{Ag}^{\delta+}$ (see Supporting Information Figure S8-S10). The $\mathrm{C} 1 s$ showed adsorbed $\mathrm{C}-\mathrm{C}, \mathrm{C}-\mathrm{O}$ and $\mathrm{C}=\mathrm{O}$ species at room temperature, however, once heated to reaction temperature no detectible amount of carbon was present on the surface (see Supporting Information Figure S7). The valence band showed signals indicative of copper oxides, as elaborated later. 
a) Low Cu Concentration (0.5 At.\%)

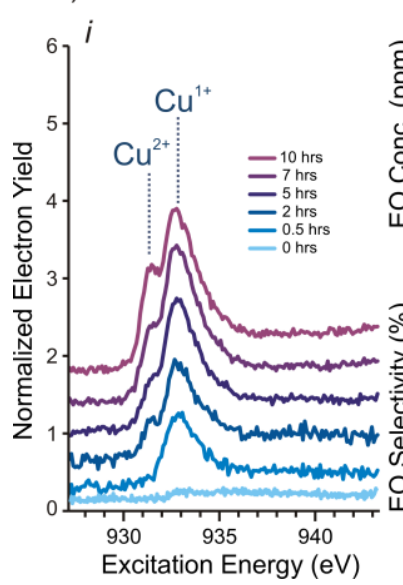

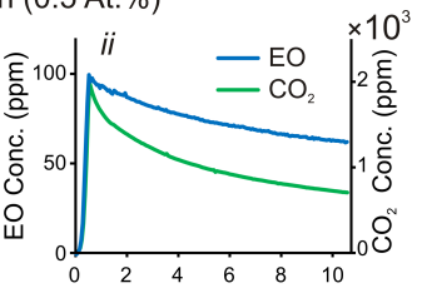

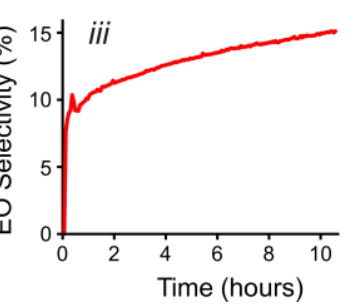

b) High Cu Concentration (2 At.\%)

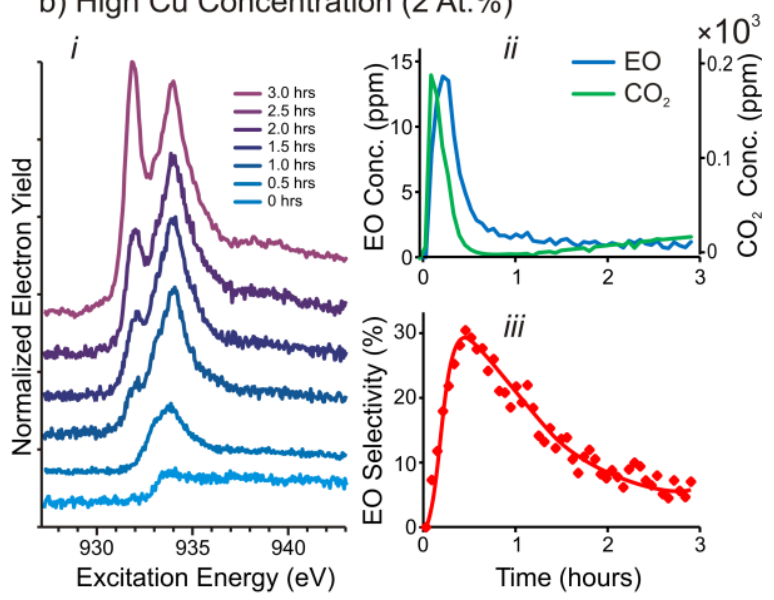

Figure 2 - Near-ambient-pressure NEXAFS data for AgCu alloys of a) dilute Cu concentration (0.5 at. \%) and b) high Cu concentration (2 at. \%). Panels i) show the Cu $L_{3}$ spectra measured with time-on-stream. From bottom to top, spectra were measured at increasing time-on-stream. Panels ii) and iii) show the corresponding activity and selectivity data, respectively.

Online product analysis of these samples showed that the sample with dilute $\mathrm{Cu}$ concentration exhibited a much higher activity compared to the sample of high $\mathrm{Cu}$ concentration. The epoxide selectivity of the dilute alloy surpassed $15 \%$ as it approached steady state, with a concomitant $50 \%$ decrease in overall activity. In contrast, the concentrated alloy reached a transient maximum in selectivity of $30 \%$, which rapidly decreased to $7 \%$. At the maximum on selectivity, the catalyst surface contained primarily $\mathrm{Cu}^{1+}$. As the selectivity decreased with time, the $\mathrm{Cu}^{2+}$ contribution increased. Alloys of several other copper concentrations were tested, with $\mathrm{Cu} L_{3}$ spectra and GC product analysis measured for each. In general, the $\mathrm{Cu}^{2+}$ concentration increases with $\mathrm{Cu}$ concentration (i.e. the alloy's behavior resembles that of pure $\mathrm{Cu}$ ).

a)

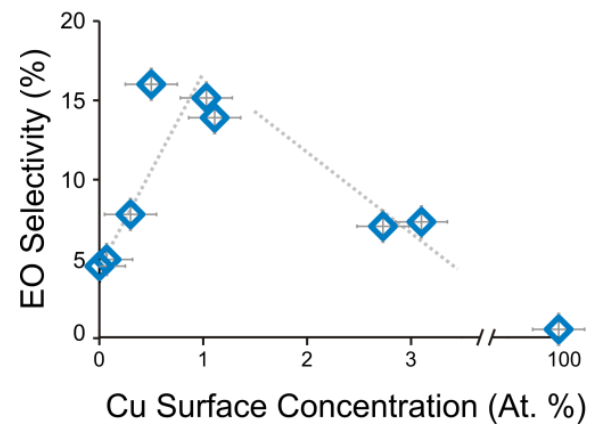

b)

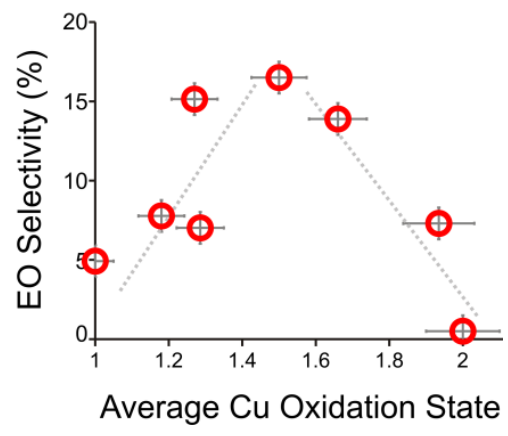

Figure 3 - Plot of selectivity to epoxide as a function of a) Cu surface concentration and b) average $C u$ oxidation state (as determined from the $C u L_{3}$ spectra) Dashed lines are used to highlight the general trends.

Figure 3 shows trends of epoxide selectivity versus (a) the alloy's bulk copper concentration, and (b) the oxidation state of surface copper. Note that, copper segregates to the surface in the presence of $\mathrm{O}_{2}$. Therefore, the surface copper concentration measured under reaction conditions is not the same as the bulk copper concentration. However, the surface and bulk concentrations are correlated. The trend between epoxide selectivity and copper surface concentration, shown in Figure 3(a), illustrates that small amounts of copper increase the catalyst's selectivity to epoxide, and too much copper eventually poisons the catalyst. The copper concentration for which the maximum selectivity occurs is similar to previously reported values. ${ }^{3,4}$ Figure 3(b) reveals a general trend between average copper oxidation state and epoxide selectivity. The reason for this trend is that the copper oxidation state is correlated to 
the copper concentration. As copper concentration increases, the catalyst progressively resembles pure copper, as copper-rich phases precipitate from the alloy. The thermodynamically most stable oxide on pure copper under these conditions is $\mathrm{CuO}$ (i.e. $\mathrm{Cu}^{2+}$ ). Thus increasing copper concentration gives rise to an overall increase in $\mathrm{Cu}^{2+}$. Interestingly, this observation also implies that the presence of $\mathrm{Ag}$ stabilizes copper in the $1+$ oxidation state. From Figure $3 \mathrm{~b}$ it appears that the surface contains a mixture of oxidation states under the conditions for optimal selectivity. This may be a spurious correlation, but it may also suggest that either a mixed $\mathrm{Cu}$-oxide or phase transition plays a role in epoxidation.

\subsection{Structural changes to the alloy in reaction conditions: In-situ electron microscopy}

While the NAP-XPS results provide some valuable insight into the surface processes that are occurring on the active catalyst's surface, due to the lack of spatial resolution (ca. $150 \mu \mathrm{m} \times 80 \mu \mathrm{m}$ spot size) the spectra can say very little about the actual structures of the surface phases that are formed. For insight into this aspect of the catalyst, we turn to in-situ ESEM.

Figure 4 shows images from an in-situ ESEM investigation of a dilute (ca. 0.5 at. \%) $\mathrm{AgCu}$ alloy powder under ethylene epoxidation conditions $\left(0.3 \mathrm{mbar}, 1: 1 \mathrm{O}_{2}: \mathrm{C}_{2} \mathrm{H}_{4}, 300^{\circ} \mathrm{C}\right)$. A video of the morphological changes that occurred is available in Supporting Information. During the initial stages (first hour) the alloy surface appears to facet and roughen. With time, dark spots appear along the facets. In some regions, a crust resembling the morphology of an oxide forms and spreads over portions of the surface. Other regions remain 'clean' and smooth like the surface of the original reduced alloy. The steady-state structure contains a mixture of several morphologies (apparent phases).
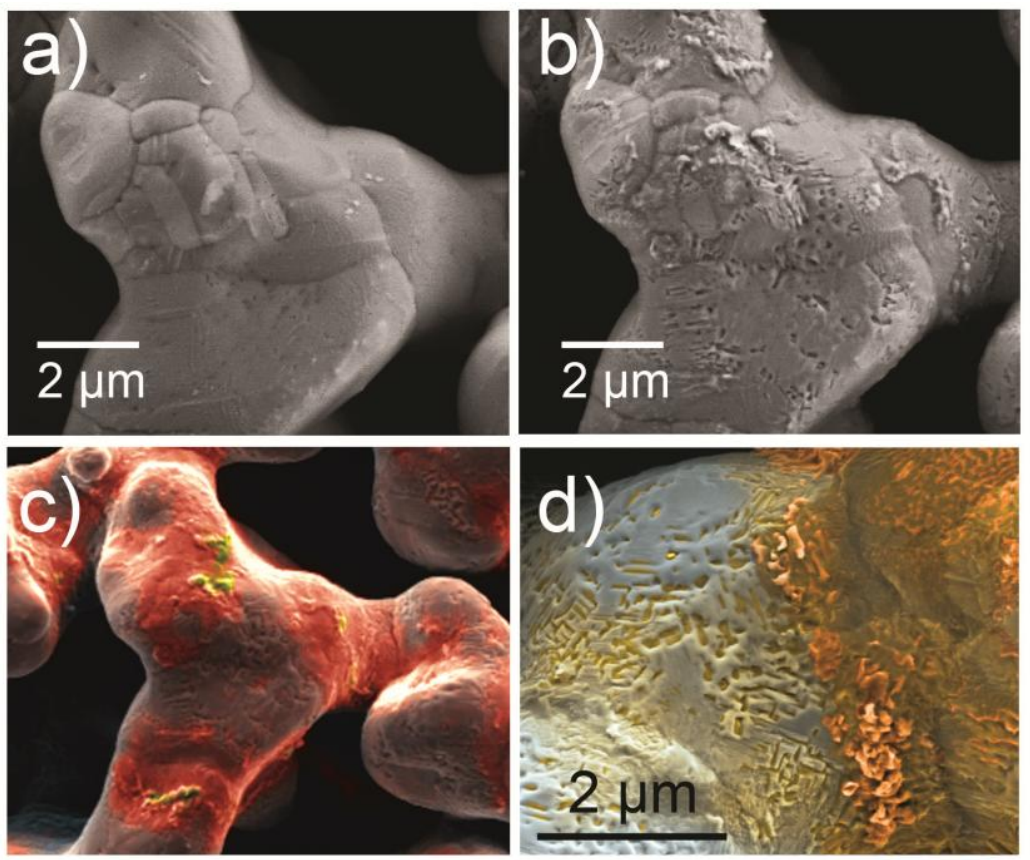

Figure 4 - a) an ESEM image of a dilute $\mathrm{AgCu}$ alloy in its reduced state, prior to oxidation (measured in-situ in an $\mathrm{H}_{2}$ atmosphere); b) ESEM image of the same area after 4 hours of time-on-stream in 0.3 mbar 1:1 $\mathrm{O}_{2}: \mathrm{C}_{2} \mathrm{H}_{4}$, at $\left.300^{\circ} \mathrm{C} ; \mathrm{c}\right)$ EDX map of the Cu L emission line overlaid onto an SEM image, measured post-reaction; d) detailed SEM image of the oxidized alloy catalyst post reaction (image is colored to highlight the variety of morphologies present at steady state). 
An EDX map, measured post-reaction, reveals the distribution of copper over the oxidized alloy surface. Additional EDX maps are available in the Supporting Information (Figure S1-S2). Figure 4c shows a map of the $\mathrm{Cu} L$ emission intensity overlaid onto an SEM image of the same area. A 'fire' color-scale is used in this image, such that yellow regions represent the highest copper concentration. One can see by comparison between the images in Figure $4 \mathrm{~b}$ and $\mathrm{c}$ that the faceted areas appear to have little copper, the 'crust' is the richest in copper (and also oxygen, as seen from the O K map in SI), and the third type of morphology-characterized by a relatively smooth non-faceted structure-has a moderate copper concentration. Figure 4d shows an artificially colored SEM image to highlight the various types of morphology typically observed on the oxidized dilute $\mathrm{AgCu}$ alloys.

Based on the EDX maps, we assume that the 'crust' morphology (colored orange in Figure 4d) is a highly oxidized form of copper (probably $\mathrm{CuO}$ ). The intermediate morphology is believed to be a copper-containing oxidic phase. The faceted regions are believed to consist of silver on the terraces with copper-containing phases formed along certain facets, giving rise to the dark regions in the cusp of the surface steps.

When oxidizing an alloy with high copper concentration the morphology during the initial stage (Figure 5b) is similar to that of the dilute-copper case; however, with extended oxidation time the surface becomes fully covered by an apparent crust (Figure 5c), covering up the faceted morphology of the partially-oxidized alloy. Based on the in-situ NEXAFS data of Figure 2b, we expect the crust to be $\mathrm{CuO}$-like, containing primarily $\mathrm{Cu}^{2+}$, while the surface during the intermediate phase of oxidation (Figure 5b) is believed to consist of both $\mathrm{Cu}^{1+}$ and $\mathrm{Cu}^{2+}$ species.
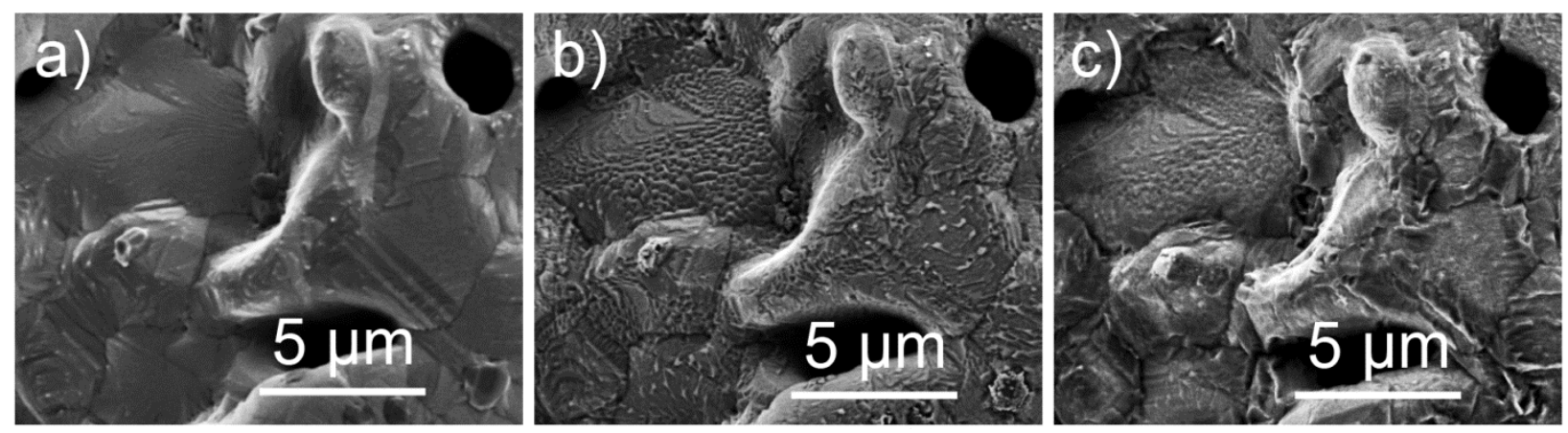

Figure 5 - ESEM images measure in-situ during ethylene epoxidation (0.3 mbar 1:1 $\left.\mathrm{O}_{2}: \mathrm{C}_{2} \mathrm{H}_{4}, 300^{\circ} \mathrm{C}\right)$ of a $\mathrm{AgCu}$ alloy of high copper concentration (ca. 5 at. \%). a) reduced alloy surface prior to oxidation, $b$ ) initial stages of oxidation, c) after 4 hours of time-on-stream.

While in-situ ESEM provides some insight into the non-uniformity and variety of phases that exist on the alloy surface during epoxidation, one cannot unambiguously identify the chemical/electronic structure of the phases present because EDX provides only elemental and not electronic-structure information. Thus, from this data, one cannot determine whether the surface oxides are simply the thermodynamically stable copper oxides $\left(\mathrm{CuO}\right.$ and $\left.\mathrm{Cu}_{2} \mathrm{O}\right)$ or whether some unique meta-stable form of oxide is present, such as those predicted by ab-initio thermodynamics. ${ }^{10}$

\subsection{Signatures of a novel oxide}

In-situ NEXAFS and valence band spectra can provide some insight into this issue. Figure 6a shows the $\mathrm{Cu} L_{3}$ spectrum of a dilute $\mathrm{AgCu}$ alloy during epoxidation, along with reference spectra of $\mathrm{CuO}$, $\mathrm{Cu}_{2} \mathrm{O}$ and $\mathrm{Cu}$. It becomes apparent that the $\mathrm{Cu}^{1+}$ absorption signal in the alloy during epoxidation is not identical to the $\mathrm{Cu}^{1+}$ absorption signal of $\mathrm{Cu}_{2} \mathrm{O}$. The $\mathrm{Cu}^{1+}$ peak maximum is shifted, for the oxidized alloy, by $0.8 \mathrm{eV}$ towards lower excitation energy relative to $\mathrm{Cu}_{2} \mathrm{O}$, while the $\mathrm{Cu}^{2+}$ peak of the 
oxidized alloy is essentially identical to the peak of $\mathrm{CuO}$. For comparison-and to ensure the peak position of the reference $\mathrm{Cu}_{2} \mathrm{O}$ sample was properly calibrated-we oxidized a $\mathrm{Cu}$ foil to the point that its surface contained a mixture of $\mathrm{CuO}$ and $\mathrm{Cu}_{2} \mathrm{O}$ (orange spectrum in Figure 6 a). Here one can clearly see that the relative positions of the $\mathrm{Cu}^{1+} / \mathrm{Cu}^{2+}$ peaks of the reference spectra are correct and that the oxidized copper formed on the alloy is not merely a mixture of $\mathrm{Cu}_{2} \mathrm{O}$ and $\mathrm{CuO}$.
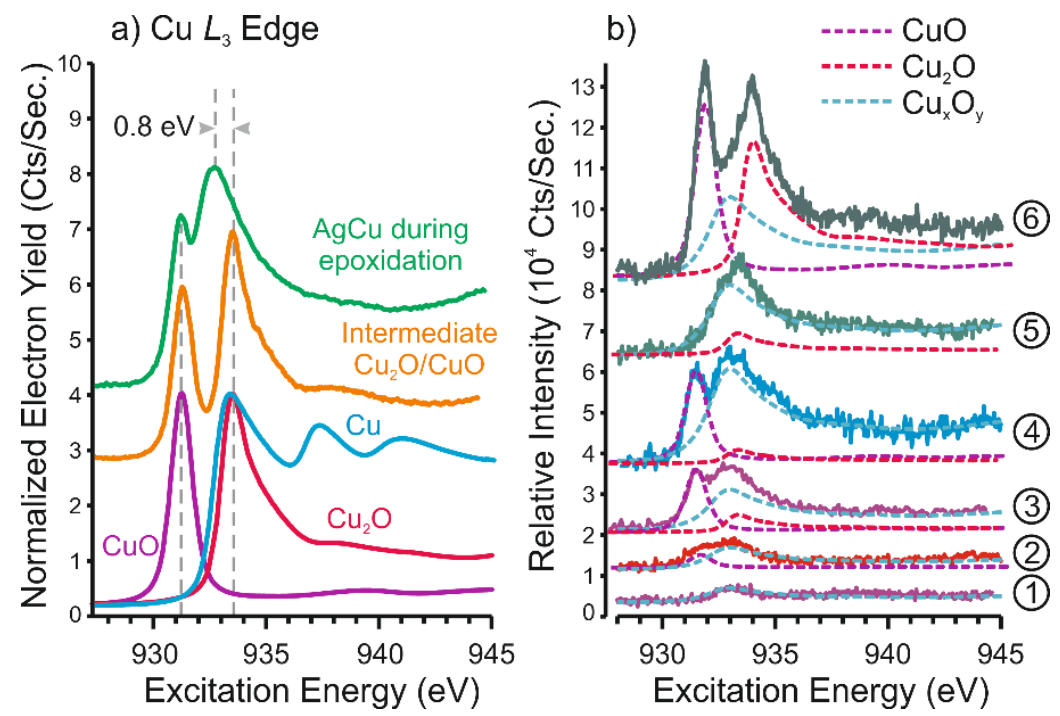

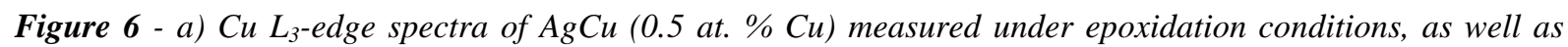
$\mathrm{Cu}_{2} \mathrm{O}, \mathrm{CuO}$ and $\mathrm{Cu}$ reference spectra, and a spectrum of an oxidized $\mathrm{Cu}$ foil showing a mixture of $\mathrm{Cu}_{2} \mathrm{O}$ and $\mathrm{CuO}$. b) A selection of $\mathrm{Cu} \mathrm{L}_{3}$-edge spectra of various $\mathrm{AgCu}$ samples measured under epoxidation conditions. All spectra can be fit with a combination of $\mathrm{CuO}, \mathrm{Cu}_{2} \mathrm{O}$ reference spectra and the addition of a third component of an unknown oxidized form of copper (blue dashed line). In panel b) the labeled spectra are: (1) AgCu with $0.1 \%$ $\mathrm{Cu}$, at steady state, exhibiting 5\% EO selectivity;(2) $\mathrm{AgCu}$ with $0.3 \% \mathrm{Cu}$ at steady state, exhibiting 8\% EO selectivity;(3) $\mathrm{AgCu}$ with $0.5 \% \mathrm{Cu}$ at steady state, exhibiting 15\% EO selectivity; (4) with $1 \%$ Cu at steady state, exhibiting $14 \%$ EO selectivity (5) $\mathrm{AgCu}$ with $2 \% \mathrm{Cu}$, measured at the maximum in EO selectivity of $30 \%$; (6) same sample as in (5) but measured at steady state, exhibiting $7 \%$ EO selectivity.

Using a principle component analysis (PCA) algorithm in CasaXPS 2.3.19 on a large set of $\mathrm{Cu} L_{3}$ spectra under changing conditions, we find that three components are needed to describe the $\mathrm{Cu} L_{3}$ data (as elaborated in the Supporting Information Figure S12). Two of the components are $\mathrm{CuO}$ and $\mathrm{Cu}_{2} \mathrm{O}$, and the third is a previously unreported spectrum. The $\mathrm{Cu} L_{3}$ spectrum of this unknown $\mathrm{Cu}_{\mathrm{x}} \mathrm{O}_{\mathrm{y}}$ species was fit using a synthetic curve to the spectrum in Figure 6a, labeled ' $\mathrm{AgCu}$ during epoxidation' and used as a vector for fitting all other spectra. As shown in Figure 6b), using a combination of $\mathrm{CuO}$, $\mathrm{Cu}_{2} \mathrm{O}$ and the just-mentioned $\mathrm{Cu}_{\mathrm{x}} \mathrm{O}_{\mathrm{y}}$ reference spectrum, all spectra of the $\mathrm{AgCu}$ catalysts during insitu conditions could be adequately fit. At very low $\mathrm{Cu}$ concentrations, and during the initial phases of oxidation, the spectra consist of primarily the $\mathrm{Cu}_{\mathrm{x}} \mathrm{O}_{\mathrm{y}}$ species (see the bottom two spectra of Figure $6 \mathrm{~b}$ ). With increasing reaction times and increasing $\mathrm{Cu}$ concentrations, $\mathrm{CuO}$ and $\mathrm{Cu}_{2} \mathrm{O}$ components become more dominant (see the top two spectra of Figure 6b).

The second-to-top spectrum in Figure $6 \mathrm{~b}$ (spectrum labeled 5) is taken from the data set of Figure $2 \mathrm{~b}$. It was measured at the maximum in epoxide selectivity for the concentrated $\mathrm{AgCu}$ alloy. This spectrum contains a mixture of $\mathrm{CuO}, \mathrm{Cu}_{2} \mathrm{O}$ and $\mathrm{Cu}_{\mathrm{x}} \mathrm{O}_{\mathrm{y}}$. The top-most spectrum in Figure $6 \mathrm{~b}$ is from the same data set, after the catalyst has deactivated. $\mathrm{The} \mathrm{Cu}_{\mathrm{x}} \mathrm{O}_{\mathrm{y}}$ species has become a minor component compared to $\mathrm{CuO}$ and $\mathrm{Cu}_{2} \mathrm{O}$. For dilute $\mathrm{AgCu}$ alloys, the $\mathrm{Cu} L_{3}$ spectra show that the $\mathrm{Cu}_{\mathrm{x}} \mathrm{O}_{\mathrm{y}}$ species is the dominant species in the high-selectivity state. The spectrum labelled 3 in Figure $6 \mathrm{~b}$ is taken from the same data set as Figure 2a-I, where an epoxide selectivity of $15 \%$ was observed. These correlations 
between epoxide selectivity and the presence of the $\mathrm{Cu}_{\mathrm{x}} \mathrm{O}_{\mathrm{y}}$ species suggests that this species may play a role in the enhanced selectivity of $\mathrm{AgCu}$ alloys.

In order to investigate the occupied electronic structure of this $\mathrm{Cu}_{\mathrm{x}} \mathrm{O}_{\mathrm{y}}$ species, we have measured valence band photoemission spectra of a dilute alloy at the very onset of oxidation (i.e. before the appearance of multiple oxides). For this purpose we exposed a $\mathrm{AgCu}$ foil $(0.3 \mathrm{at}$. $\% \mathrm{Cu}$ ) to an oxygenlean epoxidation feed containing 1:500 $\mathrm{O}_{2}: \mathrm{C}_{2} \mathrm{H}_{4}(0.3 \mathrm{mbar})$ at $250^{\circ} \mathrm{C}$, then progressively increased the $\mathrm{O}_{2}$ concentration in steps $(0.2,0.4,0.8,1.6,3.2$ and $12 \%)$. The spectra were measured using a photon energy of $150 \mathrm{eV}$-close to the Cooper minimum for $\mathrm{Ag} 4 d$-to suppress the $\mathrm{Ag} 4 d$ signal so that the spectra are more sensitive to the $\mathrm{Cu} / \mathrm{O}$ density of states. These spectra are shown in Figure 7a. One can see that the intensity of the $\mathrm{Cu} 3 d$ states (binding energy $\sim 3 \mathrm{eV}$ ) ${ }^{9,18,19}$ increases as $\mathrm{O}_{2}$ partial pressure increases and oxidized $\mathrm{Cu}$ accumulates at the surface. One can also discern an $\mathrm{O} 2 p$-based state arising at a binding energy of ca. 1-2 eV., $9,18,19$

What is intriguing about these spectra is how the line-shape of the oxidized copper component compares to that of $\mathrm{Cu}_{2} \mathrm{O}$. The copper/oxygen-based states of Figure 7a bear some resemblance to $\mathrm{Cu}_{2} \mathrm{O}$; however, when one subtracts the silver-states from the spectrum (i.e. by subtracting the spectrum of the non-oxidized surface) and compares to a reference spectrum of $\mathrm{Cu}_{2} \mathrm{O}$, it becomes clear that the valence features of the slightly-oxidized $\mathrm{AgCu}$ surface are unique, as shown in Figure $7 \mathrm{~b}$. For instance, the peak at $2-3 \mathrm{eV}$ (composed primarily $\mathrm{Cu} 3 d$ states) ${ }^{19}$ is significantly narrower for the oxidized alloy, and shifted to higher binding energy compared to the $\mathrm{Cu}_{2} \mathrm{O}$ reference spectrum. Furthermore, the shoulder at ca. $1-2 \mathrm{eV}$ (representing mixed $\mathrm{Cu} 3 d-\mathrm{O} 2 p$ states) ${ }^{19}$ is significantly smaller on the alloy, and shifted to higher binding energy by ca. $0.8 \mathrm{eV}$ compared to $\mathrm{Cu}_{2} \mathrm{O}$. These findings, combined with the observed differences in the $\mathrm{Cu} L_{3}$ spectra, suggest that the oxide formed during initial oxidation of $\mathrm{AgCu}$ has an electronic structure different from the known copper oxides. The oxidized copper species seen here, may resemble those proposed in the first-principles studies by Piccinin et. al. ${ }^{10}$

a) Valence Band

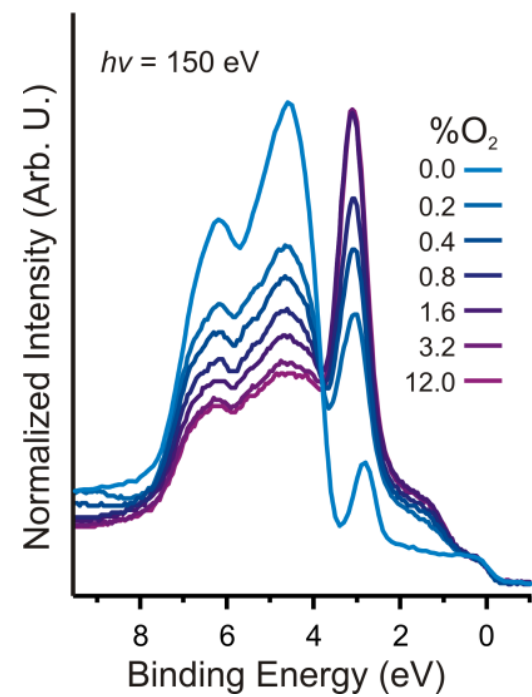

b) Valence Band Difference

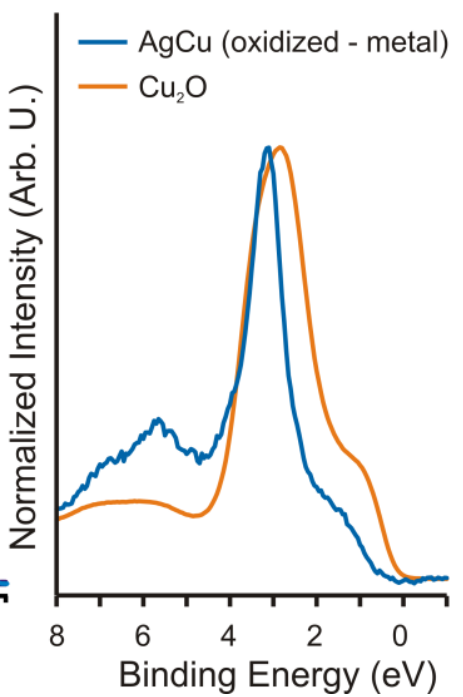

Figure 7- a) Valence band spectra measured at the Ad 4d Cooper minimum (hv=150 eV) of AgCu (0.3 at. \% $\mathrm{Cu}$ ) under increasingly oxidative epoxidation conditions $\left.\left(250^{\circ} \mathrm{C}, 0.3 \mathrm{mbar}\right) . \mathrm{b}\right)$ A difference spectrum, made by subtracting a reduced $\mathrm{AgCu}$ spectrum from a partially oxidized $\mathrm{AgCu}$ spectrum, overlaid with a reference spectrum of $\mathrm{Cu}_{2} \mathrm{O}$.

\subsection{Chemical state inhomogeneity}


Given that the NAP-XPS spectra above are not spatially resolved-having an X-ray spot size of $150 \mu \mathrm{m}$ $\times 80 \mu \mathrm{m}-$ one cannot necessarily conclude whether the spectra represent a single phase of mixed oxidation state, or a non-uniform spatial distribution of multiple phases. Indeed, as the ESEM measurements shown above had indicated, multiple phases can coexist and non-homogenously cover the catalyst's surface. To examine the spatial distribution of oxidized copper species, we have utilized a spatially resolved form of XPS in which zone plates are used to focus the X-ray beam to a spot size of $150 \mathrm{~nm}$ diameter. A map of the $\mathrm{Cu} 2 p_{3 / 2}$ intensity of an oxidized $\mathrm{AgCu}(0.3$ at. $\% \mathrm{Cu}$ ) foil is shown in the inset of Figure 8, along with $\mathrm{Cu} 2 p_{3 / 2}$ spectra from selected points (as indicated in the image). Several other areas of the sample were measured (see Supporting Information Figure S16-S17), and the spectra show here are representative. Note that the foil sample exhibited the same spectroscopic and morphological behavior as the pressed alloy powders used for the NAP-XPS and ESEM experiments, as demonstrated in the Supporting Information (Figure S5-S7).

Prior to the spatially resolved XPS measurements, the foil was cleaned by 30 minutes of argon sputtering, annealed in $\mathrm{H}_{2}$ for 30 minutes at $700^{\circ} \mathrm{C}$, then exposed to 0.3 mbar of $1: 1 \mathrm{C}_{2} \mathrm{H}_{4}+\mathrm{O}_{2}$ at $250^{\circ} \mathrm{C}$ for 5 hours. Note that the sample was removed from reaction conditions for the spatially resolved XPS measurements. While the change in conditions is expected to change the adsorbed carbon and oxygen species present on the surface, as well as possibly change the stability of the oxide phases, the kinetics of such a transformation is expected to be slow at room temperature. For comparison, a $\mathrm{Cu} 2 p_{3 / 2}$ spectrum measured with non-spatially resolved in-situ NAP-XPS is also shown. The XPS maps reveal that there are regions of the surface that are covered only by $\mathrm{Cu}^{1+}$ species, and other regions that consist of a mixture of $\mathrm{Cu}^{1+}$ and $\mathrm{Cu}^{2+}$. The presence of $\mathrm{Cu}^{2+}$ is inferred based on the satellite structure and shoulder in the $\mathrm{Cu} 2 p_{3 / 2}$ spectrum, as indicated by the black arrows in Figure $8 .{ }^{18}$ The region of mixed $\mathrm{Cu}^{1+}$ and $\mathrm{Cu}^{2+}$ is peculiar, as it indicates that either an oxide phase exists that contains a mixture of $\mathrm{Cu}^{1+}$ and $\mathrm{Cu}^{2+}$, or that the spot size of $150 \mathrm{~nm}$ was still too large to spatially resolve separate oxide domains. Spatially resolved XPS studies with higher spatial resolution would be necessary to conclude this issue.

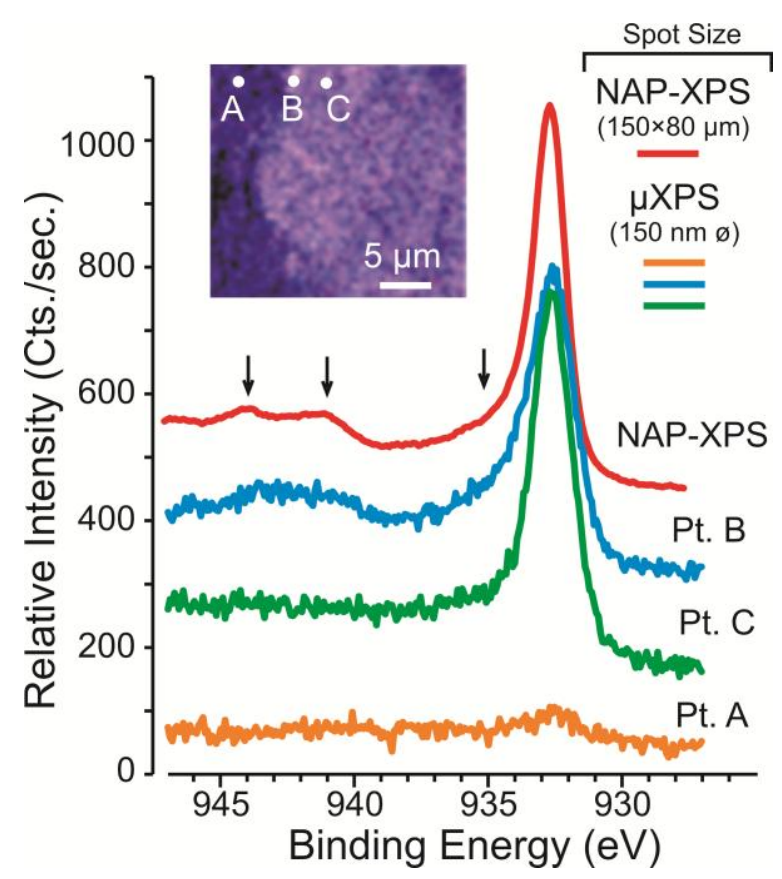

Figure 8 - Cu 2 $p_{3 / 2}$ XPS spectra $(\mathrm{hv}=1053 \mathrm{eV})$, using a focused X-ray source (spot size $\left.=150 \mathrm{~nm}\right)$, of several spots on an oxidized $\mathrm{AgCu}$ foil $\left(0.3\right.$ at. \% Cu). The inset image shows a map of the $\mathrm{Cu} 2 p_{3 / 2}$ intensity. The points from which the spectra were taken are indicated in the inset figure. For comparison, a $\mathrm{Cu} 2 p_{3 / 2}$ spectrum of an 
$\mathrm{AgCu}$ foil measured in NAP-XPS conditions $\left(0.3\right.$ mbar, 1:1 $\left.\mathrm{C}_{2} \mathrm{H}_{4}, 250^{\circ} \mathrm{C}\right)$ using and X-ray spot size of $150 \mu \mathrm{m} \times$ $80 \mu m$, is shown. The satellite and main line of the $\mathrm{Cu}^{2+}$ species are indicated by black arrows.

\section{Discussion}

The present findings show that the enhanced selectivity and activity observed for $\mathrm{AgCu}$ catalysts is correlated with the coexistence of $\mathrm{Cu}^{1+}$ and $\mathrm{Cu}^{2+}$ species and the formation of an unidentified $\mathrm{Cu}_{\mathrm{x}} \mathrm{O}_{\mathrm{y}}$ species. High copper concentrations give rise to the growth of a CuO-like overlayer on the catalyst surface and consequent deactivation. The formation of the CuO-like layer is in agreement with theoretical work that has predicted bulk copper oxides are stable at high copper concentrations. ${ }^{10}$ This finding also explains the plateau in selectivity observed by Linic et. al. with increasing copper concentrations. ${ }^{4}$ In particular, as the copper content increases, the catalyst behavior approaches that of $\mathrm{CuO}$. Previous work on copper-oxide catalysts in ethylene epoxidation has shown that $\mathrm{CuO}$ exhibits both poor epoxide selectivity and poor activity. ${ }^{9,12}$

In contrast, when the copper concentration is kept relatively low (i.e. less than 1\%)-whereby the catalyst exhibits it optimum in selectivity and activity-a multitude of oxide phases coexist on the catalyst surface, with a spatially non-homogenous distribution of copper oxidation states and some regions consisting of a mixture of $\mathrm{Cu}^{1+} / \mathrm{Cu}^{2+}$. In addition to the co-existence of multiple oxidation states, these alloys exhibit spectroscopic evidence of an oxide phase with a unique electronic structure, different from known copper oxides $\mathrm{CuO}$ and $\mathrm{Cu}_{2} \mathrm{O}$. The existence of a non-CuO, non- $\mathrm{Cu}_{2} \mathrm{O}$ phase is in agreement with predictions from theoretical calculations. ${ }^{10}$ Previous ab-initio atomistic thermodynamics calculations of several proposed $\mathrm{Cu} / \mathrm{O}$-containing surface structures were used to develop a phase diagram for the $\mathrm{AgCu}$ system in an oxygen atmosphere. ${ }^{10}$ That theoretical work showed several monolayer $\mathrm{Cu}_{\mathrm{x}} \mathrm{O}_{\mathrm{y}}$ phases to be stable, and relatively close to one another in energy. It is possible that the observed spectroscopic feature results from one of these predicted meta-stable $\mathrm{Cu}_{\mathrm{x}} \mathrm{O}_{\mathrm{y}}$ surface phases. Additional experimental work is necessary to unambiguously identify the structure giving rise to this spectroscopic feature.

The reason for the in-homogeneity and phase co-existence on these alloy catalysts can be understood by considering that, under epoxidation conditions, the phase fields of several oxides are quite narrow. ${ }^{2}$ In such a scenario, relatively small fluctuations in chemical potential on a dynamically changing surface can give rise to the nucleation of multiple phases. The nucleation and growth of a given phase will give rise to further chemical potential gradients, as for example, regions of the alloy surrounding a growing oxide particle become depleted in $\mathrm{Cu}$, giving rise to lower $\mathrm{Cu}$ chemical potentials in those regions, and consequently different phase fields relative to the average of the alloy. In fact, the spatially resolved measurements shown in Figure 8 provide some evidence suggesting that some regions of surface might remain non-oxidized. If this is the case, then the theoretical approach of using a clean metallic alloy surface-as was used as a model surface in the initial theoretical work on $\mathrm{AgCu}$ in ethylene epoxidation ${ }^{4}$-could in fact be a valid model to explain the selectivity increase for such catalysts.

Given the large complexity of alloy catalysts when multiple phases exist under reaction conditions, one cannot simply identify the active site. There are many possibilities for the enhanced epoxide selectivity of such catalysts. Here we will address four possible origins of the enhance epoxide selectivity. These scenarios are illustrated pictorially in Figure 9.

First, the observation that multi-phase coexistence of surface oxides is correlated to high activity and selectivity may indicate that phase coexistence plays an active role in epoxidation. There are several 
reports in the literature where catalysts exhibit high activity when operated near phase transitions-for example in $\mathrm{CO}$ oxidation on $\operatorname{Pt}(110),{ }^{20,21} \mathrm{Pd}(100)^{20}$ and $\mathrm{RuO}_{2} \cdot{ }^{22}$ The bi-stability of phases near phase transitions allows a system to flip between states while paying essentially no energetic penalty. If the flip is coupled with a catalytic reaction or the activation of an adsorbed species, then operating under conditions near a phase transition provides high activity for a given activation step. Furthermore, the formation of meta-stable surface species close to a phase transition, can also give rise to high activity. This phenomenon was recently proposed for ethylene epoxidation on copper oxides. ${ }^{11}$ The scenario where a phase transition between any one of the several phases present on the surface plays an active role in epoxidation is depicted in Figure 9 A.

Another hypothesis is that the bulk thermodynamically stable copper oxides $\mathrm{CuO}$ and $\mathrm{Cu}_{2} \mathrm{O}$ play no role in epoxidation. Rather a monolayer $\mathrm{Cu}_{\mathrm{x}} \mathrm{O}_{\mathrm{y}}$ surface phase, similar to those predicted by Piccinin et. al., ${ }^{2}$ catalyzes epoxidation. This scenario is depicted in Figure 9 B. This explanation has a particularly firm grounding, because not only are such phases predicted to be stable under epoxidation conditions, there is also good reason why they would exhibit enhanced selectivity. Theoretical work was performed to calculate reaction barriers on these surface phases for reaction steps relevant to ethylene epoxidation. ${ }^{13}$ The work showed that ethylene epoxidation on several predicted phases should exhibit higher epoxide selectivity than on silver surfaces. The reason for this enhancement is based on the descriptor derived by Kokalj, ${ }^{23}$ namely a stronger O-surface bond relative to the $\mathrm{C}$-surface bond. The difference in bond strengths stabilizes the transition state to ethylene epoxide preferentially over the transition state to acetaldehyde. In the oxametallacycle intermediate on $\mathrm{Cu}_{\mathrm{x}} \mathrm{O}_{\mathrm{y}}$ monolayers, the $\mathrm{O}-\mathrm{Cu}$ bond is stronger than $\mathrm{C}-\mathrm{Cu}$ bond, giving rise to a lower barrier to epoxide. ${ }^{13}$ On pure $\mathrm{Ag}$ surfaces, the weak $\mathrm{O}-\mathrm{Ag}$ bond gives rise to a lower barrier to aldehyde, giving rise to lower epoxide selectivity. ${ }^{13}$ While this is an attractive explanation, there is not yet experimental evidence to confirm that such surface phases exist on alloy surfaces during epoxidation. We have found some spectroscopic evidence in the present work to indicate it might exist, but isolating such a phase will be necessary to conclusively identify it.
A) Epoxidation at one of several possible phase transitions
B) Epoxidation at $\mathrm{CuO}_{x}$ monolayer
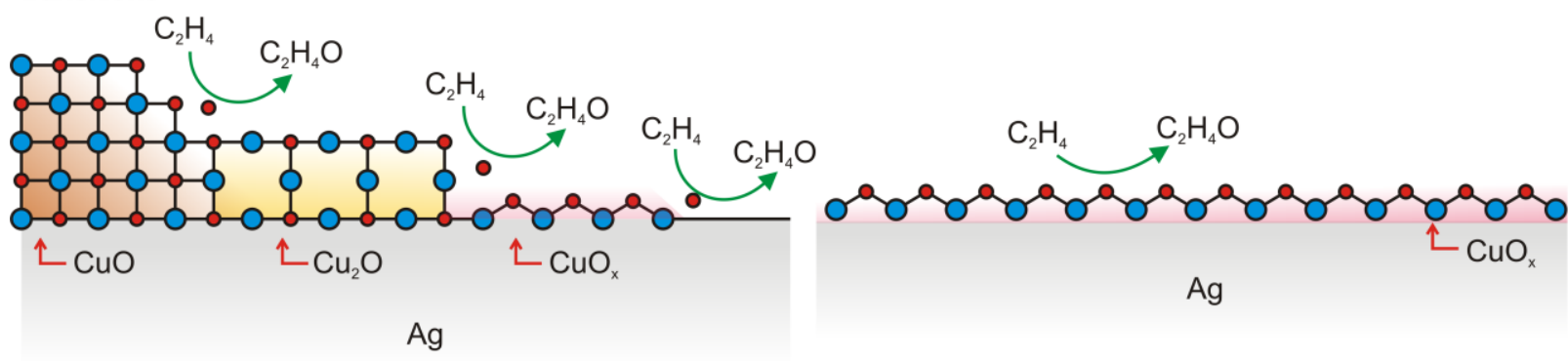

C) Cu segregation, epoxidation at metallic alloy

D) O-activation at Cu-oxide, spillover to selective $\mathrm{Ag}$ sites,

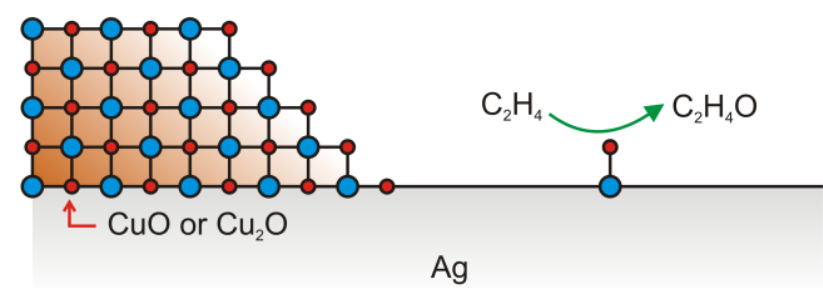
blocking of non-selective Ag sites by Cu-oxide

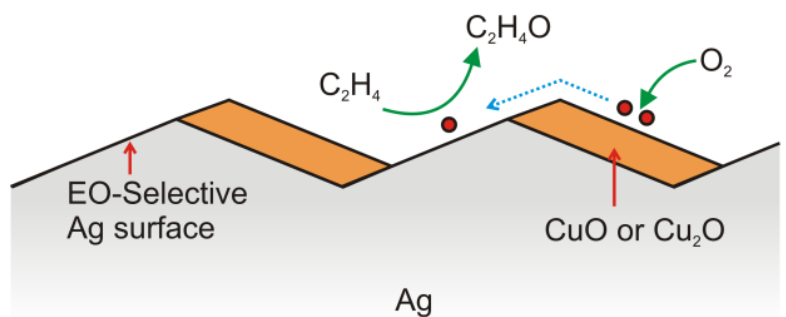

Figure 9- Illustrations of four possible explanations of the action of copper in enhancing epoxidation on $\mathrm{AgCu}$ alloys. A) The case where epoxidation is linked to a phase transition, B) the case where a CuO $\mathrm{O}_{x}$ monolayer 
performs epoxidation, $C$ ) the case where parts of the alloy's surface remain uncovered by oxide, and epoxidation occurs on the non-oxidized alloy surface, D) the case where copper oxides block non-selective sites and act as sources of $\mathrm{O}_{2}$ activation and $\mathrm{O}$-ion spillover species, while epoxidation takes place on neighboring silver surfaces. Please note, these are for illustrative purposes only. Bond lengths, bond angles and stoichiometries of the oxides are not to scale. Green arrows represent chemical reactions, blue dashed line represents surface diffusion, red arrows indicate labels.

One additional explanation is that part of the surface remains metallic during epoxidation, and the original model used to explain the selectivity enhancement of these alloys is accurate. ${ }^{4}$ This scenario is depicted in Figure $9 \mathrm{C}$. In this model, the surface is treated as metallic, with a unit cell consisting of all $\mathrm{Ag}$ atoms except for one $\mathrm{Cu}$ atom. The same descriptor as mentioned above can be used to understand epoxide selectivity on the metallic surface (i.e. O-surface versus $\mathrm{C}$-surface bond strengths determine epoxide selectivity). However in this case, the oxygen atom of the oxametallacycle intermediate is bound to both $\mathrm{Ag}$ and $\mathrm{Cu}$, while the carbon atom of the oxametallacycle is bound to only Ag. Thus, the reason for increased epoxide selectivity in this model can still be understood by an increase in $\mathrm{O}$-surface bond strength due to the presence of $\mathrm{Cu}$.

If the surface were truly to remain metallic under epoxidation conditions, with $\mathrm{Cu}$ atoms distributed over the surface, the $\mathrm{Cu}$ concentration and $\mathrm{O}$ chemical potentials would need to be extremely low. ${ }^{10} \mathrm{It}$ is therefore likely that either the surface is completely coated with some form of oxidized copper, or all the $\mathrm{Cu}$ has segregated to $\mathrm{Cu}_{2} \mathrm{O} / \mathrm{CuO}$ regions, leaving regions of pure $\mathrm{Ag}$ behind. This scenario is depicted in Figure 9 D. If this were the case, then what role would copper play? Perhaps the oxides tend to form on top of $\mathrm{Ag}$ regions that give rise to non-selective total oxidation. Covering them with a low-activity copper oxide, like $\mathrm{CuO}$, would block them and give rise to decreased $\mathrm{CO}_{2}$ production.

While this may be the case, there is evidence that copper does more than that. In particular, kinetics studies of $\mathrm{AgCu}$ catalysts in epoxidation have shown that $\mathrm{AgCu}$ catalysts are generally more active than $\mathrm{Ag}$ catalysts. ${ }^{3}$ The reaction orders for $\mathrm{O}_{2}$ and $\mathrm{C}_{2} \mathrm{H}_{4}$ are similar on $\mathrm{Ag}$ and $\mathrm{AgCu}$ catalysts, suggesting that the reaction mechanism on $\mathrm{AgCu}$ is fundamentally the same as on $\mathrm{Ag}$ catalysts. However, the $\mathrm{O}_{2}$ dissociation barrier and activation energy for ethylene consumption is significantly lower on $\mathrm{AgCu}$ than on $\mathrm{Ag} .{ }^{3}$ The reason for the lower $\mathrm{O}_{2}$ dissociation barrier is likely because copper is much more oxophilic than silver. If $\mathrm{O}_{2}$ activation is the rate-determining step, then a low $\mathrm{O}_{2^{-}}$ activation barrier would explain the higher activity of $\mathrm{AgCu}$ alloys. However, if copper's role is $\mathrm{O}_{2}$ activation, and silver's role is catalyzing epoxidation, then this would imply that either $\mathrm{Ag}$ and $\mathrm{Cu}$ sites are intimately close together, or oxygen ions spill-over from the segregated copper regions to silver regions. Oxygen spill-over would require the existence of mobile, weakly-adsorbed oxygen species. Given how strongly oxygen bonds to copper in bulk copper oxides, it seems somewhat unlikely to occur unless the process happens close to a phase transition, which could give rise to metastable, weakly-adsorbed oxygen ions. ${ }^{11}$ If one were to assume oxygen activation occurs at copper sites, and the blocking of non-selective sites on silver gives rise to enhanced selectivity, then one would still need to infer that mobile, weakly-adsorbed oxygen species can be formed at the oxidized copper sites in order to have a consistent model.

It should be clear that these are just hypothesized scenarios, and given the currently available data on such a complex system, one cannot distinguish the possible models. We emphasize that alloy catalysts on which multiple phases co-exist are complex systems, and one should be cautious about claiming something to be the active site before truly grasping the complexity in its entirety. In order to move toward a conclusive picture of such a complex system, it is important to unambiguously identify all of the structures present on the active surface. A large amount of further experimental and theoretical 
work is required to build a conclusive picture of how multiphase-coexistence on alloy catalysts influence catalytic behavior in general.

\section{Conclusions}

In-situ XPS, NEXAFS and SEM studies of ethylene epoxidation on $\mathrm{AgCu}$ alloys of various compositions has revealed that multiple oxidized copper phases can coexist on the active catalyst surface. A general trend is found whereby high-concentrations of $\mathrm{Cu}$ give rise to the formation of $\mathrm{CuO}$, decrease in epoxide selectivity and deactivation of the catalyst. In contrast, alloys with lower $\mathrm{Cu}$ concentrations (ca. 1\%) give the highest epoxide selectivities, and were observed to consist of a mixture of $\mathrm{Cu}^{1+}$ and $\mathrm{Cu}^{2+}$ species on the active surface. Furthermore, spectroscopic evidence of an oxidic $\mathrm{Cu}$ phase was discovered that is present on the active catalyst and correlated to epoxide selectivity. This oxide has spectroscopic features that are distinct from the thermodynamically most stable $\mathrm{Cu}$ oxides $\left(\mathrm{CuO}\right.$ and $\left.\mathrm{Cu}_{2} \mathrm{O}\right)$. This species could play an important role in the epoxide selectivity enhancements of $\mathrm{AgCu}$ alloys. Further studies are underway to conclusively identify the structure of this species and to determine its epoxidation activity. Several hypotheses are proposed to explain the origin of epoxide selectivity increase on this multi-phase alloy catalyst.

\section{Acknowledgements}

We would like to thank the Max-Planck Gesellschaft and the Alexander von Humboldt Foundation for their generous funding. We would also like to thank the Max-Planck Gesellschaft and the HelmholtzZentrum Berlin for use of their infrastructure.

\section{Associated Content}

Videos 1 and 2 show ESEM images measured in-situ during ethylene epoxidation on $\mathrm{AgCu}$ alloys. Figures $\mathrm{S} 1-\mathrm{S} 2$ show EDX maps of $\mathrm{Ag}, \mathrm{Cu}$ and $\mathrm{O}$ from the $\mathrm{AgCu}$ alloys, post reaction, used in the ESEM studies. Figure S3 shows Cu2p, valance band, O1s, and $\mathrm{Ag} 3 \mathrm{~d}$ spectra measured in-situ during epoxidation on a $\mathrm{AgCu}$ alloy $(0.5 \% \mathrm{Cu})$. Figure $\mathrm{S} 4$ shows the $\mathrm{Cu} 2 \mathrm{p}, \mathrm{O} 1 \mathrm{~s}$ and valence band spectra measured in-situ during the dilute- $\mathrm{O}_{2}$ experiments (i.e. those associated with Figure 7). Figure S5 shows SEM images and EDX maps of a $\mathrm{AgCu}$ foil before, during and after ethylene epoxidation. Figure S6-S7 shows $\mathrm{Cu} 2 \mathrm{p}, \mathrm{Ag} 3 \mathrm{~d}, \mathrm{O} 1 \mathrm{~s}, \mathrm{C} 1 \mathrm{~s}$, valence band and $\mathrm{Cu} L_{3}$ spectra measured in-situ during epoxidation on a $\mathrm{AgCu}$ foil $(2 \% \mathrm{Cu})$. Figure $\mathrm{S} 8$ shows a comparison of $\mathrm{Ag} 3 \mathrm{~d}$ spectra from $\mathrm{AgCu}$ alloys of $2 \%$ and $0.5 \% \mathrm{Cu}$ concentration. Figure S9 shows Ag3d and valence band spectra of a pure $\mathrm{Ag}$ foil under epoxidation conditions. Figure $\mathrm{S} 10$ shows comparisons of $\mathrm{O} 1 \mathrm{~s}$ spectra from $\mathrm{AgCu}(2 \%$ and $0.5 \%$ ) and pure $\mathrm{Ag}$ under epoxidation conditions. Figure S11 shows a principle component analysis of a series of valence band spectra of $\mathrm{AgCu}$ measured during epoxidation. Figure S12-S13 shows a principle component analysis of $\mathrm{Cu} L_{3}$ spectra measured of $\mathrm{AgCu}$ during epoxidation. Figure $\mathrm{S} 14$ shows $\mathrm{GC}$ data of $\mathrm{Ag}, \mathrm{Cu}$ and $\mathrm{AgCu}$ during epoxidation. Figure S16 shows a schematic of the GC experimental set-up. Figure $\mathrm{S} 17$ shows $\mathrm{Cu} 2 \mathrm{p}$ spectra and $\mathrm{Cu} L M M$ maps of oxidized $\mathrm{AgCu}$ measured using zone plates.

\section{References}

(1) Norskov, J. K.; Bligaard, T.; Rossmeisl, J.; Christensen, C. H. "Towards the computational design of solid catalysts" Nat. Chem. 2009, 1, 37-46.

(2) Piccinin, S.; Zafeiratos, S.; Stampfl, C.; Hansen, T. W.; Hävecker, M.; Teschner, D.; Bukhtiyarov, V. I.; Girgsdies, F.; Knop-Gericke, A.; Schlögl, R.; Scheffler, M. "Alloy Catalyst in a Reactive Environment: The Example of Ag-Cu Particles for Ethylene Epoxidation" Phys. Rev. Lett. 2010, 104, 035503. 
(3) Jankowiak, J. T.; Barteau, M. A. "Ethylene epoxidation over silver and copper-silver bimetallic catalysts: I. Kinetics and selectivity" J. Catal. 2005, 236, 366-378.

(4) Linic, S.; Jankowiak, J.; Barteau, M. A. "Selectivity driven design of bimetallic ethylene epoxidation catalysts from first principles" J. Catal. 2004, 224, 489-493.

(5) Torres, D.; Lopez, N.; Illas, F.; Lambert, R. M. "Why Copper Is Intrinsically More Selective than Silver in Alkene Epoxidation: Ethylene Oxidation on $\mathrm{Cu}(111)$ versus $\mathrm{Ag}(111)$ " J. Am. Chem. Soc. 2005, 127, 10774-10775.

(6) Cropley, R. L.; Williams, F. J.; Vaughan, O. P. H.; Urquhart, A. J.; Tikhov, M. S.; Lambert, R. M. "Copper is highly effective for the epoxidation of a "difficult" alkene, whereas silver is not" Surf. Sci. 2005, 578, L85-L88.

(7) Cowell, J. J.; Santra, A. K.; Lindsay, R.; Lambert, R. M.; Baraldi, A.; Goldoni, A. "Bonding and reactivity of styrene on $\mathrm{Cu}(110)$ : heterogeneous alkene epoxidation without the use of silver" Surf. Sci. 1999, 437, 1-8.

(8) Santra, A.; Cowell, J.; Lambert, R. "Ultra-selective epoxidation of styrene on pure $\mathrm{Cu}\{111\}$ and the effects of Cs promotion" Catal. Lett. 2000, 67, 87-91.

(9) Greiner, M. T.; Jones, T. E.; Johnson, B. E.; Rocha, T. C. R.; Wang, Z. J.; Armbruster, M.; Willinger, M.; Knop-Gericke, A.; Schlogl, R. "The oxidation of copper catalysts during ethylene epoxidation" Phys. Chem. Chem. Phys. 2015, 17, 25073-25089.

(10) Piccinin, S.; Stampfl, C.; Scheffler, M. " $\mathrm{Ag}-\mathrm{Cu}$ alloy surfaces in an oxidizing environment: A first-principles study" Surf. Sci. 2009, 603, 1467-1475.

(11) Greiner, M. T.; Jones, T. E.; Klyushin, A.; Knop-Gericke, A.; Schlögl, R. „ Ethylene Epoxidation at the Phase Transition of Copper Oxides" J. Am. Chem. Soc. 2017, 139, 11825-11832.

(12) Jayamurthy, M.; Hayden, P.; Bhattacharya, A. K. "Direct catalytic epoxidation of ethene over copper and alumina-supported copper" J. Catal. 2014, 309, 309-313.

(13) Nguyen, N. L.; de Gironcoli, S.; Piccinin, S. "Ag-Cu catalysts for ethylene epoxidation: Selectivity and activity descriptors" J. Chem. Phys. 2013, 138, 184707.

(14) Rocha, T. C. R.; Hävecker, M.; Knop-Gericke, A.; Schlögl, R. "Promoters in heterogeneous catalysis: The role of $\mathrm{Cl}$ on ethylene epoxidation over Ag" J. Catal. 2014, 312, 12-16.

(15) Rocha, T. C. R.; Oestereich, A.; Demidov, D. V.; Hävecker, M.; Zafeiratos, S.; Weinberg, G.; Bukhtiyarov, V. I.; Knop-Gericke, A.; Schlögl, R. "The silver-oxygen system in catalysis: new insights by near ambient pressure X-ray photoelectron spectroscopy" Phys. Chem. Chem. Phys. 2012, 14, 4554-4564.

(16) Bukhtiyarov, V. I.; Nizovskii, A. I.; Bluhm, H.; Hävecker, M.; Kleimenov, E.; KnopGericke, A.; Schlögl, R. "Combined in situ XPS and PTRMS study of ethylene epoxidation over silver" J. Catal. 2006, 238, 260-269.

(17) Subramanian, P. R.; Perepezko, J. H. "The ag-cu (silver-copper) system" J. Phase Equilib. 1993, 14, 62.

(18) Ghijsen, J.; Tjeng, L. H.; Vanelp, J.; Eskes, H.; Westerink, J.; Sawatzky, G. A.; Czyzyk, M. T. "The electronic structure of $\mathrm{Cu}_{2} \mathrm{O}$ and CuO" Phys. Rev. B 1988, 38, 11322-11330.

(19) Soon, A.; Todorova, M.; Delley, B.; Stampfl, C. "Surface oxides of the oxygen-copper system: Precursors to the bulk oxide phase?" Surf. Sci. 2007, 601, 5809-5813.

(20) Hendriksen, B. L. M.; Bobaru, S. C.; Frenken, J. W. M. „' Looking at Heterogeneous Catalysis at Atmospheric Pressure Using Tunnel Vision" Top. Catal. 2005, 36, 43-54.

(21) Nettesheim, S.; von Oertzen, A.; Rotermund, H. H.; Ertl, G. "Reaction diffusion patterns in the catalytic CO-oxidation on $\mathrm{Pt}(110)$ : Front propagation and spiral waves" J. Chem. Phys. 1993, 98, 9977-9985.

(22) Reuter, K.; Scheffler, M. "First-Principles Atomistic Thermodynamics for Oxidation Catalysis: Surface Phase Diagrams and Catalytically Interesting Regions" Phys. Rev. Lett. 2003, 90, 046103.

(23) Kokalj, A.; Gava, P.; de Gironcoli, S.; Baroni, S. "What determines the catalyst's selectivity in the ethylene epoxidation reaction" J. Catal. 2008, 254, 304-309. 


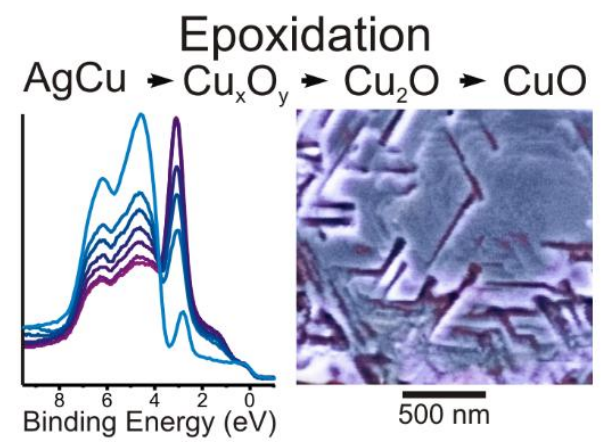

